\title{
PODER JUDICIÁRIO, REGIME AUTORITÁRIO E MEMÓRIA: A NARRATIVA INSTITUCIONAL SOBRE O REGIME AUTORITÁRIO
}

\section{JUDICIARY, AUTHORITARIAN REGIME AND MEMORY: THE NARRATIVE INSTITUTIONAL ARRANGEMENTS ON AUTHORITARIAN REGIME}

\author{
${ }^{1}$ Vanessa Dorneles Schinke
}

\section{RESUMO}

O artigo analisa, criticamente, a narrativa oficial sobre a atuação do poder judiciário durante o regime autoritário de 1964-1985, construída pelos espaços de memória da justiça comum brasileira. A partir de fontes primárias, acessadas nos arquivos judiciais, especificamente nos espaços criados para a difusão da memória institucional, coteja-se a realidade do período, de graves violações de direitos humanos e de ruptura da normalidade institucional, com narrativas produzidas pelos espaços institucionais sobre o Poder Judiciário, acerca do período. O tom laudatório e a ausência de referências ao contexto jurídico político predominam nesses fragmentos produzidos pela instituição.

Palavras-chave: Poder judiciário, Regime autoritário, Memória

\section{ABSTRACT/RESUMEN/RÉSUMÉ}

This article examines critically the official narrative about the role of the judiciary during the authoritarian regime of 1964-1985, built by the memory spaces of the Brazilian common justice. From primary sources accessed in court files, specifically in the spaces created for the dissemination of institutional memory, collates the reality of the period, of serious human rights violations and disruption of institutional normality, with narratives produced by institutional spaces on the Judiciary, about the period. The laudatory tone and the absence of references to political legal framework predominate in these fragments produced by the institution.

Keywords/Palabras-claves/Mots-clés: Judiciary, Authoritarian regime, Memory

\footnotetext{
${ }^{1}$ Doutora pela Pontifícia Universidade Católica do Rio Grande do Sul - PUC, Porto Alegre - RS (Brasil) Professora da Universidade Federal do Pampa - UNIPAMPA, Bagé - RS (Brasil).

E-mail: vanessa.schinke@gmail.com
} 


\section{INTRODUÇÃO}

Durante o último regime autoritário brasileiro, as graves violações de direitos humanos foram realizadas de forma sistemática e generalizada, contra grupos que se opunham à política do regime. As instituições, por sua vez, tiveram papel central na condução de políticas econômicas e sociais, destinadas a manter o projeto autoritário (fundado em uma concepção econômica dependente, baseada na ideologia da segurança nacional). De um lado, o Congresso Nacional confeccionou a legalidade autoritária (PEREIRA, 2010) que, embora adotando procedimentos e fórmulas legislativas esquizofrênicas, serviu para tentar confundir o regime de fato da época com um regime de direito. De outro, o Executivo construía discursos que tentavam dotar de normalidade institucional a ruptura provocada pelo golpe de 1964. Junto a esse contexto, a justiça comum manteve-se em funcionamento, ainda que alguns juízes tenham sido aposentados compulsoriamente, por motivos políticos.

O regime deu especial atenção do judiciário quando, logo em 1965, publicou o Ato Institucional $\mathrm{n}^{\mathrm{o}}$ 2, que alterada significativamente a justiça comum. Se, desde, 1964, a arbitrariedade dos atos do Executivo não poderiam ser objeto de apreciação judicial, nos termos da cláusula de exclusão prevista, pela primeira vez, no art. $7^{\circ}$ do AI-1, a partir de 1965 a justiça federal foi reinstalada e teve seus juízes nomeados pelo Presidente da República. O judiciário foi mantido, reestruturado e incrementado, principalmente no que tange à criação de Comarcas e Varas. A esta instituição coube a aplicação da legalidade autoritária (incluindo a aplicação da paradoxal cláusula de afastamento da apreciação judicial, prevista no AI-1), e a análise de casos concretos que envolviam graves violações de direitos humanos. A atuação da justiça comum durante o período não foi irrelevante. Esse espaço detinha inúmeros filtros que possibilitavam a mimetização da ruptura institucional, decorrente de um golpe civil-militar, com um fictício Estado de Direito.

Considerando esse contexto sócio-político da época, este texto se debruça, criticamente, sobre a narrativa institucional construída pelo poder judiciário sobre sua atuação, durante o regime autoritário de 1964-1985.

A partir de fontes primárias, apresenta a amarração de sentido produzida pelos espaços dedicados à memória institucional da justiça comum do Rio Grande do Sul (estadual e federal). Conforme a apresentação do material, serão perceptíveis o tom laudatório construído pela memória institucional e o destaque conferido ao foro íntimo dos juízes, elementos que pouco nos dizem sobre a qualidade do exercício das funções 
constitucionalmente atribuídas ao poder judiciário. O texto parte dos conceitos de abuso de memória, de Tzvetan Todorov (2000, p. 33), que questiona a finalidade da memória, colocando-a lado a lado, em importância, com a própria iniciativa de construir uma memória. Nesses termos, uma narrativa torna-se abusiva quando sua finalidade reitera ou silencia demasiadamente sentidos essenciais sobre a história que se pretende contar. Essa metodologia foi escolhida para operacionalizar, mais claramente, o potencial vivificador da memória, que comporta, intrinsecamente, a faculdade de romper com os nexos construídos por outras narrativas históricas que os apresentam como necessários e indissolúveis. A narrativa construída pelo próprio poder judiciário em cotejo com a narrativa tecida a partir de indícios e de fontes primárias, pretende registrar o tênue limite entre memória e esquecimento e, consequentemente, entre uso e abuso.

\section{A LÓGICA DE AÇÃO E O POTENCIAL VIVIFICADOR DA MEMÓRIA}

A lógica de ação, enquanto processo de narração do acontecido, pode acarretar a desconstrução do continuísmo ou a reiteração de que aquelas narrativas obedecem a ordenações irreversíveis (HALBWACHS, 2001, p. 33). Walter Benjamin (2002, p. 21) faz referência ao potencial revivificador da memória, que ameaça constantemente a narração que se apresenta como causal em relação ao presente.

Na memória, como construção seletiva do passado, os pontos de partida e de chegada são escolhidos pelo próprio evocador, ainda que pretenda falar em nome individual ou de um grupo (CATROGA, 2001, p. 22). Ao passo em que é impossível narrar tudo, pois é da natureza da narração o exercício de uma função mediadora entre memória e esquecimento, não há narrativa canônica. Sempre é possível narrar de outra forma, incluir ou excluir sujeitos e configurar a narrativa de outro modo.

O elemento central, para compreendermos a força irradiadora da memória institucional dentro de uma democracia, parte da admissão de que a memória, manifestada através de uma narrativa, é um exercício, uma ação, o resultado de uma disposição de contar, de determinada maneira, o que se passou. Daí o equívoco de compreendê-la como algo recebido, como um recipiente que tudo acolhe, passivamente, sem discriminação. Antes de ser construída, ela foi buscada. Os fragmentos que conferem sentido à determinada narrativa foram construídos, analisados e encaixados.

O empenho na construção da narrativa não é, portanto, uma busca por alguma verdade, tal qual um objeto afundado, que precisa ser resgatado. Não há, nesse sentido, 
objeto pronto. Esse movimento que se volta para o passado parte de necessidades e preocupações presentes.

As circunstâncias que integram a narrativa não foram agraciadas pelo altruísmo e pela generosidade de quem narra, saindo do esquecimento para uma superfície de reconhecimento. Ao contrário, as partes da narrativa são escolhidas conforme as angústias, as necessidades e os objetivos de quem a tece.

\section{FRAGMENTOS DA NARRATIVA PRODUZIDA PELO JUDICIÁRIO}

A Apresentação do projeto Histórias de Vida, que reúne entrevistas com juízes da justiça estadual do Rio Grande do Sul, parte de uma preocupação: “o Brasil não cultua o judiciário" (SOUZA, 1999). ${ }^{1}$ A narrativa da memória institucional avisa que será construída, portanto, a partir do viés que indica a necessidade de uma cultura do Poder Judiciário. Decorre dessa problemática o sentido da afirmação de que "o Projeto Memória do Judiciário, visa institucionalizar uma cultura do judiciário” (SOUZA, 1999).

\footnotetext{
O povo não aprendeu a amá-lo. As elites desdenham-no. Os políticos o desapreciam. Os demais poderes temem a sua afirmação, dada a competência constitucional de controlar os seus atos. Os meios de comunicação o desvirtuam, por desconhecê-lo. $\mathrm{O}$ Poder Judiciário continua “esse desconhecido". [...] Quantas obras significativas foram publicadas no Brasil neste século sobre o Poder ou sobre os seus membros mais ilustres? Não alcançarão uma dezena, por certo. (SOUZA, 1999, p. 2). ${ }^{2}$
}

O culto ao judiciário, apresentado nesses termos, reivindica a construção de uma memória institucional que se insere em uma democracia, dentro da qual o judiciário exerce suas funções, cujas finalidades são delineadas para melhor sedimentar o próprio regime democrático. A interface entre a construção de uma narrativa de culto ao judiciário e sua pertinência ao regime democrático, portanto, indicará as inconsistências ou os potenciais de manutenção desses moldes de narrativa.

\footnotetext{
1 Nelson Oscar de Souza, autor do texto da Apresentação, foi desembargador do Tribunal de Justiça do Rio Grande do Sul, cargo que assumiu em 1981

2 O trecho "esse desconhecido" faz alusão à obra de Aliomar Baleeiro, publicada em 1968.
} 
Em 2012, o Tribunal de Justiça do Rio Grande do Sul publicou uma atualização da obra originalmente intitulada Tribunal de Justiça do RS - 125 anos de história (18741999).

Nas páginas iniciais da nova publicação, merece destaque a frase do então Coordenador do Memorial do Judiciário do Rio Grande do Sul: “o preceito vetor da administração do poder judiciário é a supremacia da dignidade deste poder" (FÉLIX, 2012, p. 11). A mensagem subliminar dessa afirmação sugere que a narrativa sobre o poder judiciário é uma louvação ao próprio judiciário.

A justiça comum do Rio Grande do Sul possui espaços especialmente destinados à memória institucional. Inaugurado em 2013, o Memorial da Justiça Federal do Rio Grande do Sul tem a missão de incentivar, divulgar, interpretar e amparar a preservação histórica e do patrimônio da Seção Judiciária do Rio Grande do Sul: “é um espaço que privilegia a cultura e a memória institucional, atuando na preservação do patrimônio cultural e na divulgação da história da Justiça Federal gaúcha”. Em seu documento de divulgação, há referência à finalidade de deixar "um registro na sociedade sobre a identidade institucional do judiciário e promover uma reflexão sobre ela" (JUSTIÇA FEDERAL).

Na justiça estadual, o Centro de Memória do Judiciário Gaúcho foi criado em 2000 e, em 2002, passou a se chamar Memorial do Judiciário do Estado do Rio Grande do Sul. Integrante do Gabinete da Presidência do Tribunal de Justiça, é coordenado por um desembargador designado pelo Presidente do Tribunal. O Memorial tem a missão de "resgatar e preservar a memória do judiciário gaúcho, analisando os dados em qualquer de suas formas - e favorecendo sua difusão na comunidade".

Como gestos exemplares, as solenidades regulares da instituição cumprem um papel ritualístico: o tempo do ritual é um tempo do sagrado, marcado pela repetição de um gesto exemplar, que, quando reiterado, remete os envolvidos a um instante mítico do princípio. ${ }^{3}$ Os rituais judiciários, para François Ost, destinam-se a alimentar a tradição, com base na sua própria continuidade e anterioridade, compreendendo-a como fonte inesgotável de autoridade (OST, 2001, p. 106).

\footnotetext{
3 Para Mircea Eliade (1993, p. 50), o homem arcaico tem medo do evento, que traz a mudança, o que o leva a evitá-lo através da repetição contínua de gestos inaugurais. Durante os rituais, o tempo profano ficaria suspenso, havendo uma projeção para um tempo mítico. O tempo do ritual é um tempo do sagrado, marcado pela repetição de um gesto exemplar, que, quando reiterado, remete os envolvidos a um instante mítico do princípio.
} 
Nas suas primeiras linhas, a obra Tribunal de Justiça do RS: mais de um século de história afirma que o historiador soleniza a recordação, fazendo "desfilar no palco do presente os fastos antigos, dignificando a visão pretérita e valorizando o construído" (GIORGIS, 2012, p. 10). A história, conforme a publicação, resume-se à narração de um grupo de acontecimentos. Essa linearidade, no enfrentamento de construção de uma narrativa que se volta para o passado, reflete-se na apresentação das origens do Memorial do Judiciário do Rio Grande do Sul, relatada através de uma sucessão de atos normativos. ${ }^{4}$ A postura institucional que compreende o passado como indisponível - remetendo ao falacioso encaixe causal, referido por Walter Benjamin (2002) - é respaldada pelo tom laudatório que anuncia que a ilibada história daquela instituição será contada:

\begin{abstract}
Desvelada a importância e fincados os laços genéticos entre os institutos (memória e história), ressoa como proeminente a pesquisa e afirmação da identidade do Poder Judiciário sulino, buscando-se acumular, através das diversas técnicas de investigação, os dados que fortaleçam a política de visibilidade e transparência de um passado honroso, fonte de inspiração para uma atualidade exitosa; e perspectivas de venturoso porvir. (GIORGIS, 2012, p. 10).
\end{abstract}

Esses rituais, ao mesmo tempo em que indicam a pertença ao grupo, apontam para um sentimento de continuidade. Paradoxalmente, também delimitam a fronteira entre os que se identificam e, assim, podem compartilhar os privilégios do grupo pela herança do pedigree, e os excluídos. As cerimônias que marcam a transmissão de cargos de chefia, na cúpula do judiciário nacional, são exemplos paradigmáticos da atenção que os rituais judiciários possuem na narrativa institucional. Logo após a promulgação da Constituição Federal, José Nery da Silveira - que iniciou sua carreira na justiça federal de primeira instância no Rio Grande do Sul -, foi saudado pelo ministro Sydney Sanches, pela posse no cargo de Presidente do Supremo Tribunal Federal. Nesse discurso de felicitação, fica latente a crença de que a legitimidade da instituição é alimentada pela tradição ritualística:

\footnotetext{
${ }^{4}$ Em 23 de janeiro de 1998, Portaria assinada pelo Presidente do Tribunal de Justiça, Desembargador Adroaldo Furtado Fabrício, criou o Projeto Memória. O início das atividades ocorreu em 6 de julho do mesmo ano, já na Presidência do Desembargador Cacildo de Andrade Xavier. Mais tarde, pela Portaria no 35/2000-P, de 11 de outubro de 2000, o Projeto converteu-se em Centro de Memória do Judiciário Gaúcho. E somente mediante a Portaria n ${ }^{\circ}$ 01/2002, assinada pelo então Presidente, Desembargador Luiz Felipe Vasques de Magalhães, em 09 de janeiro de 2002, o Centro transformou-se em Memorial do Judiciário do Estado do Rio Grande do Sul. Em 29 de janeiro do mesmo ano, foram inauguradas as novas instalações no andar térreo do Palácio da Justiça (TRIBUNAL D EJUSTIÇA DO RIO GRANDE DO SUL, 2015).
} 
Interrompem-se os pregões de julgamento, as sustentações dos advogados, os votos dos juízes, os debates acesos, a proclamação dos resultados. Contêm os litigantes sua ansiedade. Recolhem-se os processos. É hora da tradição. De passagem de direção. De transmissão de comando. Há, porém, no silêncio da Corte, o perpassar da emoção. A reiteração bienal do acontecimento, se revela tranquilidade da sucessão, na cúpula do Judiciário nacional, não reduz, jamais, a importância do acontecimento. (SUPREMO TRIBUNAL FEDERAL, 1989, p. 6).

Ao lado dos ritos, Fernando Catroga (2001, p. 24) defende não haver representação memorial sem traços. O sentido da narrativa que se move através de referências espaçostemporais também se insere nas disputas semânticas da sociedade, contribuindo com processos de reiteração ou de desconstrução de hierarquias, exclusões e identificações. Nessa linha, Reyes Mate também insere o simbolismo atribuído aos lugares entre os processos de trazer à tona o significado do que se pretende estar ali representado. Decorre desse entendimento o sentido da afirmação de que "o abandono do lugar físico tem a ver com o esquecimento de sua significação".

A função social da memória - o agir semântico da memória -, presente no momento da re-presentificação, ou seja, no ato de repetir a narrativa, é materializada através de liturgias próprias, no ato de indicar vestígios do que não existe mais. A luta semântica que se estabelece no ato de rememorar é indissociável da sua espacialização. Daí a ideia de que lugares de memória só evocam algum acontecimento se lhes é atribuído um valor simbólico.

Portanto, seu conteúdo (da memória) é inseparável, não só das expectativas em relação ao futuro, como dos seus campos de objectivação - linguagem, imagens, relíquias, lugares, escrita, monumentos - e dos ritos que o produzem e transmitem; o que mostra que ela nunca se desenvolverá, no interior dos sujeitos, sem suportes materiais, sociais e simbólicos de memória. (CATROGA, 2001, p. 23). 
As narrativas construídas pelos espaços de memória da justiça comum concedem especial atenção aos espaços físicos. Da deferência ao que esses espaços contêm ou representam, foram publicadas diversas obras, com a finalidade específica de identificar, fisicamente, os rastros do judiciário no Rio Grande do Sul. Dentre as publicações, merecem destaque As Sedes do Tribunal ${ }^{5}$, Um Palácio para a Justiça ${ }^{6}$, Cadernos de Pesquisa: História Administrativa das Comarcas $^{7}$, em que consta o mapa das comarcas (1809-2002) e, não por acaso, a jurisdição submetida à competência do magistrado. A referência à jurisdição alude ao espaço submetido à autoridade de determinado juiz. De forma quase pragmática, traduz física e visualmente que, naquela região, há um representante da identidade do poder judiciário.

A memória sobre as sedes dos tribunais, além de provocar associações pela variação dos traços arquitetônicos, ao longo do tempo, sinaliza que aquele espaço abriga um representante do poder judiciário e que os ritos e as tradições da instituição desenvolvem-se naqueles limites.

A série "O Poder Judiciário no Rio Grande do Sul”, publicada originalmente em 1974 e reimpressa em 2010, reúne diversos artigos, divididos em dois volumes. ${ }^{8} \mathrm{~A}$ Apresentação da obra, feita originalmente em fevereiro de 1974, foi redigida pelo Presidente do Tribunal de Justiça, que recordou, em tom profético, o juramento que os primeiros juízes prestaram, em 1874, ao assumirem seus cargos:

\footnotetext{
5 A publicação destina-se a divulgar a história das três sedes do Tribunal de Justiça do Estado do Rio Grande do Sul, desde a sua implantação, em 1874. Ricamente ilustrada, a publicação apresenta a história de cada um dos prédios que abrigaram a Justiça de $2^{a}$ instância no Estado (A Casa da Duque, a Casa de Câmara e o Palácio da Justiça) e sua importância para a memória da cidade de Porto Alegre, montando um paralelo entre a história das sedes do Tribunal e a evolução arquitetônica e urbana da cidade. A publicação ainda serve como base para a exposição de painéis temáticos sobre as sedes do Tribunal de Justiça que se encontra em exposição aberta ao público no saguão de entrada do Palácio da Justiça, em Porto Alegre (BIANCAMANO, s/d).

${ }^{6}$ O livro é resultado de um convênio entre o Memorial do Judiciário do RS e o Tribunal de Justiça do Rio Grande do Sul com o Programa de Pesquisa e Pós-Graduação em Arquitetura da UFRGS (PROPAR/UFRGS), contém centenas de fotografia - algumas delas inéditas - ao longo dos seis capítulos que compõem a obra. Os textos e ilustrações detalham os fatos relacionados com o concurso de anteprojetos, realizado no ano de 1952, e as diversas propostas apresentadas. Encerra analisando o projeto vencedor e seus autores.

7 Essa publicação traz as seguintes informações: nome da comarca; data de criação; endereço da sede do foro e jurisdição (TRIBUNAL DE JUSTIÇA DO RIO GRANDE DO SUL, 2003, v. I).

8 O primeiro volume é composto pelos seguintes artigos: "A justiça comum de 2 a instância"; "A justiça comum de

$1^{a}$ instância" e "O Poder Judiciário no Rio Grande do Sul”. Integram o segundo volume: "A Justiça Eleitoral no Rio Grande do Sul”; "A Justiça Militar no Rio Grande do Sul"; "Resumo histórico da Justiça Militar no Estado"; "A Justiça do Trabalho no Rio Grande do Sul"; "A Justiça Federal no Rio Grande do Sul"; "O Ministério Público no Rio Grande do Sul"; "Panorama jurídico do Rio Grande do Sul"; "Apontamentos sobre as justiças e alguns de seus magistrados, no sul do Brasil, durante o período colonial"; "Sobre um acórdão"; "Uma longa demanda" e "Efemérides judiciárias rio-grandenses" (NEQUETE, 2010, v. I e v. II).
} 
Comemora hoje o Tribunal de Justiça do Estado, com justificado orgulho, o seu primeiro centenário. Seus 7 primeiros juízes disseram, a 3 de fevereiro de 1874: "Juro cumprir exatamente os deveres do meu cargo". E o mais novo deles, empossado a 31 de agosto de 1973, repetiu a fórmula, ainda que com outras palavras: "Prometo desempenhar com exatidão os deveres do cargo de Desembargador. (NEQUETE, 2010). ${ }^{9}$

No espaço reservado aos Presidentes do Tribunal de Justiça do Rio Grande do Sul, João Clímaco de Mello Filho (que, no dia 3 de abril de 1964, assinou a mensagem solicitando que o III Exército fizesse uso da força para conter o movimento da segunda legalidade, no Rio Grande do Sul) é descrito com predicados de cunho personalíssimo: “a escolha do novo desembargador foi muito bem acolhida nos meios forenses, dados os aprimorados dotes de cultura e de inteligência" (NEQUETE< 2010, p. 132). João Clímaco de Mello Filho foi nomeado desembargador, em 1945, pelo Tenente-Coronel Ernesto Dornelles, que era o interventor federal no Rio Grande do Sul. Todavia, não há menção ao Estado Novo nem às peculiaridades autoritárias da época. ${ }^{10} \mathrm{O}$ magistrado assumiu o cargo de Presidente do TJRS em março de

1964, permanecendo até 1966, período que abrangeu o AI-1, que previu pela primeira vez a cláusula de exclusão da apreciação judicial, e o AI-2, que alterou, substancialmente, a organização judiciária brasileira. Não obstante, nada consta sobre o cenário político nacional ou regional: "findo seu mandato, que exercera com proficiente maestria, voltou a integrar uma das Câmaras, continuando, com sua peculiar serenidade e perfeito equilíbrio, a distribuir justiça” (NEQUETE, 2010, p. 133).

Carlos Thompson Flores, $20^{\circ}$ Presidente do Tribunal de Justiça e nomeado ministro do Supremo Tribunal Federal, por Costa e Silva, em 1968, é apresentado a partir do seu pedigree judicial: "nascido em 26 de janeiro de 1911 [...] neto do Desembargador

\footnotetext{
9 O desembargador, nomeado em 31 de agosto de 1973, referido pelo Presidente do Tribunal de Justiça nessa Apresentação, foi um dos juízes de direito que, em 1968, aplicou a cláusula de exclusão da apreciação judicial, prevista no $\$ 4^{\circ}$, art. $7^{\circ}$, do AI-1 (RIO GRANDE DO SUL, 1968).

10 Nomeado por Getúlio Vargas, Ernesto Dornelles foi interventor federal, no Rio Grande do Sul, entre 1943-1945.
} 
Carlos Thompson Flores" (NEQUETE, 2010, Tomo I, p. 133). Na entrevista que concedeu para o projeto Histórias de Vida, o magistrado também registra sua estirpe: "meu avô paterno, o desembargador Carlos Thompson Flores, foi o fundador e primeiro diretor da Faculdade de Direito de Porto Alegre, hoje integrante da Universidade Federal do Rio Grande do Sul" (FÉLIX, 1999, p. 156). O período de sua carreira, que coincide com o regime autoritário, é descrito pelo eixo da sucessão de cargos ocupados:

Fez, no Tribunal de Justiça, parte do Conselho Superior da Magistratura, tendo sido eleito Vice-Presidente do Tribunal para o biênio 1964/1965, e, de 1966 a março de 1968, ocupou a Presidência do Tribunal de Justiça. [...] Encontrava-se o Desembargador Carlos Thompson Flores já no último mês de seu mandato de Presidente do Tribunal de Justiça e preparava-se para retornar a uma de suas Câmaras quando veio a ser convidado e a ser nomeado para, como um de seus Ministros, integrar o Egrégio Supremo Tribunal Federal. Nessa Suprema Corte continuou o Ministro Carlos Thompson Flores, como sempre o havia feito em toda sua brilhante carreira de magistrado, a distribuir justiça, o que tem feito com a mesma elevação e serenidade, dando sobeja demonstração do acerto de sua escolha para o Excelso Pretório e contribuindo, assim, para mais elevar o nome da magistratura de seu Estado natal. (NEQUETE, 2010, v. I, p. 135).

A ideia de continuidade entre o regime democrático e o regime autoritário pode ser identificada na narrativa institucional que elenca os juízes da justiça estadual que ascenderam a cargos de competência nacional. A narrativa institucional não diferencia as nomeações ocorridas durante os regimes democrático ou autoritário. A narrativa de Carlos Thompson Flores, que integra o acervo do Memorial do Judiciário do Rio Grande do Sul, ilustra que os cargos ocupados durante o regime autoritário compõem o mais privilegiado eixo de memória sobre o período:

Nesse período constituiu-se uma geração que iria desempenhar relevante posição na vida política do Estado e do Brasil, como, por exemplo, Mem de Sá, posterior mente Senador da República e Ministro da Justiça, [...] Eloy da Rocha (Deputado Federal, Secretário de Estado, Desembargador do Tribunal de Justiça e Ministro do Supremo Tribunal Federal). (FÉLIX, 1999, v. I, p. 156).

Além disso, a ocupação desses cargos, sem mais, é descrita como um indicador da importância da magistratura estadual. Automaticamente, a nomeação para cargos de maior hierarquia qualifica a entidade de origem, sem que sejam feitas considerações sobre a forma pela qual esses magistrados aplicam o direito. A "plêiade da representação gaúcha", como é descrita por uma publicação do Tribunal de Justiça, inclui juízes que atuaram durante o regime autoritário, que ocuparam cargos administrativos de chefia na justiça estadual, nesse 
período, e que foram nomeados, para os tribunais superiores, pelos militares (FÉLIX, 2012, p. 143).

No Superior Tribunal de Justiça (STJ), Ministro Athos Gusmão Carneiro, que foi Desembargador do TJRS (1977-1989) e Ministro do STJ (1989-1993) e Ministro Ruy Rosado de Aguiar Júnior, que foi Desembargador no TJRS (1985-1994) e Ministro do STJ (1994-2003). Ao Supremo Tribunal Federal (STF) ascenderam: Ministro Pedro Affonso Mibieli; Ministro Plínio de Castro Casado; Ministro Carlos Maximiliano; Ministro Armando de Alencar; Ministro Eloy da Rocha; Ministro Carlos Thompson Flores e Ministro Pedro Soares Muñoz. (FÉLIX, 2012, p. 144).

Em 2009, Athos Gusmão Carneiro foi entrevistado na série Cadernos de Memória, publicada pelo Memorial do Judiciário do Rio Grande do Sul. Na ocasião, um dos entrevistadores, função desempenhada por outros magistrados, registrou as carreiras exitosas dos magistrados nomeados para o Supremo Tribunal Federal. Todos os juízes mencionados foram nomeados durante o regime autoritário.

Des. Donato João Sehnem - O Des. Athos Gusmão Carneiro é nosso eterno Desembargador, sem dúvida nenhuma, mas chegou a Ministro do Superior, e é uma honra para todos nós, do Judiciário do Rio Grande do Sul, termos nossos magistrados valorizados nos Tribunais Superiores do País. No Supremo, tivemos vários Desembargadores, aliás, com quem eu convivi aqui no Tribunal, como Carlos Thompson Flores, Eloy José da Rocha, Pedro Soares Muñoz. (SEHNEM, 2009, v. II, p. 13).

Como visto, as narrativas sobre a história do judiciário utilizam, como referência, as sucessões de sedes, gestões e comarcas: "o trabalho se debruça sobre o Tribunal de Justiça do Rio Grande do Sul, seus desembargadores em todos os tempos e gestões desde os períodos mais recuados, encerrando-se com o rol das comarcas gaúchas" (GIORGIS, 2012, p. 10). ${ }^{11} \mathrm{O}$ padrão do acervo institucional sobre a história da justiça comum, no Rio Grande do Sul, segue essa metodologia.

\footnotetext{
11 A ideia é reiterada na Apresentação da obra: "No capítulo 1 é examinada a Justiça no Brasil até a instalação do Tribunal da Relação [...]. No capítulo 2, o centro das atenções já se direciona especificamente para examinar o funcionamento da 'Justiça de $1^{\text {a }}$ Instância'. Nele fizemos uma opção temática (as comarcas) e uma cronológica (a diacrônica), examinando o tema desde os inícios da justiça colonial no RS (finais do séc. XVIII e inícios do XIX) até a primeira década do século XXI. O enfoque central do capítulo é a criação e a transformação de comarcas e termos e de suas distribuições regionais, visando a perceber, através de uma linha de continuidade do processo histórico-jurídico, quais foram as mudanças e as permanências ao longo do tempo em um mesmo espaço" (FÉLIX, 2012, p. 19-20).
} 
O período do regime autoritário também é apresentado através desse recorte: sucessões de sedes, gestões e comarcas. ${ }^{12}$ Não raro, a narrativa limita-se a descrever o posicionamento do magistrado dentro da estrutura administrativa do judiciário. $\mathrm{O}$ mesmo eixo de narração aparece no texto A justiça federal no Rio Grande do Sul, escrito pelo juiz João Cesar Leitão Krieger, um dos primeiros magistrados a atuar na justiça federal, no Rio Grande do Sul, logo após sua reinstalação pelo AI-2. Nessa obra, a narrativa trilhada pela sucessão de nomes de juízes federais e de normas que criavam e extinguiam varas federais é explícita:

Rediviva a Seção deste Estado, para a qual inicialmente, estavam previstas três varas, cada uma com dois juízes, um federal e outro federal substituto, após indicação de nomes pelo saudoso Presidente Humberto Castello Branco, o Senado Federal aprovou, no que diz com este Estado, por unanimidade, os nomes dos indicados. Tendo havido desistência de alguns deles, ao cabo somente tomaram posse, perante o eminente conterrâneo Américo Godoy Ilha, então Presidente do Tribunal Federal de Recursos, o Juiz Federal José Néri da Silveira, hoje também Ministro daquele alto colegiado, no qual torna patente o seu saber, e como juízes federais substitutos Hermillo Galant e o autor destas modestas memórias. (NEQUETE, 2010, v. II, p. 105).

Mais do que confundir a memória da instituição sobre o regime autoritário com a carreira dos juízes, a narrativa construída pelos espaços institucionais coloca em primeiro plano a vida funcional dos magistrados. Essa abordagem, além de personalizar as atribuições funcionais desses servidores públicos, nada registra sobre o exercício e a qualidade das funções jurisdicionais:

Em 1974, fui promovido para o Tribunal de Alçada. Antes, fui escolhido como Substituto do Tribunal de Alçada, mas não cheguei a exercer. Jurisdicionei nesta qualidade a $1^{a}$ Câmara Cível até agosto de 1977, quando fui promovido para o Tribunal de Justiça e classificado para a $2^{a}$ Câmara Cível, jurisdição que exerci até 1988. (FÉLIX, 1999, v. I, p. 203).

12 Esse padrão reflete-se na disposição de temas, na página eletrônica do Tribunal de Justiça do Rio Grande do

Sul. O endereço eletrônico do Tribunal de Justiça possui uma entrada chamada "História". Esse item subdivide-se 
Ao discorrer sobre o poder judiciário, no período republicano (que na publicação vai de 1889 a 2011), listam-se as comarcas existentes, o número de juízes e de desembargadores. Ao encerrar, a obra elenca a nominata de desembargadores, por antiguidade, e as gestões administrativas do Tribunal de Justiça. ${ }^{13}$ Não constam, nas 223 páginas desse livro, quaisquer vocábulos que possam remeter, ainda que genericamente, ao contexto político brasileiro de 1964-1985. Na linha do tempo, construída pelo Memorial da Justiça Federal, o período do regime autoritário aparece com as seguintes entradas:

1965 -Reinstalação do $1^{\circ}$ Grau através do Ato Institucional n 2, de 1965, que criou uma Seção Judiciária para cada estado e uma para o Distrito Federal, com sedes nas capitais;

1967 -Reinstalação da Justiça Federal no Rio Grande do Sul - A Justiça Federal retomou seu funcionamento em maio de 1967, com três varas federais, nas dependências do prédio conhecido como "Palacinho", localizado na Avenida Cristóvão Colombo, em duas salas emprestadas pela administração estadual. Os primeiros juízes foram José Néri da Silveira, Hermillo Shamann Galant e João Cézar Leitão Krieger. No mesmo ano, se transfere para o Edifício Protetora, no centro de Porto Alegre;

1971 - Surgimento dos processos em massa- Reorganização do Sistema Financeiro da Habitação devida à apuração de falhas no sistema anterior ocasiona o surgimento dos chamados processos em massa, com a mesma demanda (envolvendo a casa própria), mas diferentes autores;

1978 - Democratização- Em 15 de junho de 1978, o casal Bauermann entrou com uma ação ordinária contra o INPS, questionando os cálculos da sua aposentadoria. Em

17 de novembro de 1980, o juiz Jirair Aram Maguerian proferiu sentença julgando a ação procedente e condenando o INPS a reajustar o benefício. A partir dessa decisão, centenas de milhares de processos foram ajuizados em todo Brasil, com o mesmo objetivo;

1983 - Início da informatização- Em 25 de novembro de 1983, foram inaugurados os serviços de informática com a autorização do sorteio para a distribuição dos processos criminais, além do cadastramento dos feitos e o lançamento de fases. Em 1987, os sistemas processuais foram unificados. Na metade da década de 1990, foi disponibilizada a primeira página na internet, e as unidades administrativas iniciaram a operação em rede;

1987 - Interiorização- Começa o processo de interiorização da $1^{\text {a }}$ Instância. A primeira vara criada no interior, na cidade de Rio Grande, foi instalada em maio; 1988 - A nova Constituição Federal estabeleceu mudanças significativas para a cidadania. Nesse contexto, emergiram novas demandas sobre o Poder Judiciário, com a criação de instrumentos como os Juizados Especiais e a Defensoria Pública (JUSTIÇA FEDERAL, s/d).

\footnotetext{
em: História do Poder Judiciário; Nominata Histórica de Desembargadores; Gestões Anteriores; Sedes do Poder Judiciário e Memorial do Judiciário do Rio Grande do Sul (TRIBUNAL DE JUSTIÇA DO RIO GRANDE DO SUL, 2015).

13 Curiosamente, ao final, a obra faz menção a uma suposta estabilidade institucional, que vigorou desde o fim do Estado Novo: "Com o ingresso no país em uma relativa normalidade democrática, o Judiciário do Rio Grande do Sul passou a ter, desde 1945, uma alternância mais regular no poder, como pode ser observado na lista de Presidentes e seus respectivos períodos. O Judiciário também passou a exercer sua prerrogativa de eleição interna e de mandatos de dois anos, situação que se mantém até hoje" (FÉLIX, 2012, p. 154).
} 
Curiosamente, nesse material, o ano de 1967 retrata as alterações de sede da justiça federal, o número de varas e o nome dos juízes da época. Essa narrativa sobre a justiça federal no Rio Grande do Sul condensa todas as chaves de leitura utilizadas pelos espaços de memória da justiça comum, ao passo que apaga o contexto político do país. Apesar de mencionar que a justiça federal foi criada pelo AI-2, não há alusão à natureza da norma, a quem a outorgou ou ao regime da época.

A única referência clara ao regime autoritário, feita pelos Memoriais da justiça comum, é um folheto publicado em outubro de 2014. No item Ditadura, listam-se os seguintes acontecimentos: suspensão de direito políticos de alguns dos membros do judiciário; bipartidarismo; alteração de competência para a Justiça Militar dos crimes contra a segurança nacional; eleições indiretas e a Lei de Imprensa, que instituiu a censura.

Em 13/12/1968, o AI-5 enfeixou poderes discricionários nas mãos do Presidente da República. Houve o fechamento do Congresso Nacional por 10 meses; a suspensão das garantias de vitaliciedade e inamovibilidade dos juízes; a exclusão de qualquer apreciação judicial dos atos praticados conforme o AI e seus Atos Complementares; a cassação de Ministros do Supremo, a redução da composição da Corte, de 17 para 11 membros; a restrição do habeas corpus; a limitação do uso de recursos extraordinários aos Tribunais e a abolição do recurso ordinário nos casos de mandados de segurança denegados pelos Tribunais. (TRIBUNAL DE JUSTIÇA DO RIO GRANDE DO SUL, 2014). ${ }^{14}$

${ }^{14} \mathrm{O}$ material divide-se nas seguintes seções: Modelo Jurídico Português e a Justiça no Brasil Colônia; Justiça no Império; A República Velha; República Nova; Ditadura; Reabertura Política até 2012. Ao todo, o folheto possui 14 páginas. 
Paradoxalmente, após elencar, brevemente, traços de um regime autoritário, a publicação destaca que "em contrapartida, o judiciário expandiu-se, acompanhando o ritmo do progresso econômico e do crescimento populacional. A jurisdição federal de $1^{\mathrm{a}}$ instância foi restabelecida" (TRIBUNAL DE JUSTIÇA DO RIO GRANDE DO SUL, 2014). Na obra $O$ poder judiciário no Rio Grande do Sul, a única referência, genérica, relativa aos anos do regime autoritário, aparece quando mencionada a origem do Tribunal de Alçada. Curiosamente, o livro destaca que o Tribunal de Alçada foi criado através da Lei $\mathrm{n}^{\circ} 6.174$, de 27 de dezembro de 1974, com base na competência conferida pelo art. 144, §5º da Emenda Constitucional $\mathrm{n}^{\mathrm{o}} 1$, de 17 de outubro de 1969. 15

A natureza autoritária da norma que outorgou a competência para o Presidente do Tribunal de Justiça não foi questionada. Nessa linha, as referências à cúpula militar do regime também são naturalizadas harmoniosamente nas narrativas:

Quando fui Presidente da AJURIS, já como desembargador, foi encaminhado pelo Presidente Médici um projeto de lei instituindo a Lei Orgânica da Magistratura Nacional, que nós convencionamos chamar de LOMAN. A remessa ao Congresso foi em 1977 ou 1978. (FÉLIX, 1999, v. I, p. 208). ${ }^{16}$

A narrativa institucional traz à tona justificativas para que a justiça comum tenha aplicado a legalidade autoritária, conforme a doutrina de fato: "o problema é que cada juiz pode ter o seu critério sobre a justiça ou injustiça legal, e irá deixar de aplicá-la. Como? Só poderia fazê-lo se a norma fosse considerada inconstitucional” (SEHNEM, 2009, v. II, p. 15). A exemplo da atuação dos juízes durante o regime, que investiram a legalidade

\footnotetext{
15 Na cerimônia de instalação do Tribunal de Alçada, o discurso do Presidente do Tribunal de Justiça agradece ao Governador do Estado, Walter Peracchi Barcellos, e a Assembleia Legislativa do Estado, por terem transformado as disposições constantes de resolução em lei, o que permitiu a criação do Tribunal de Alçada: "Pela criação desse órgão julgador manifestou-se o Tribunal ao tê-lo incluído na Resolução que baixou em 26 de agosto do ano findo,

a respeito da divisão e organização judiciárias do Estado. Essa providência, bem como outras que se recomendavam para melhor aparelhar o Poder Judiciário estadual na magnitude de sua missão de distribuir justiça, encontrou pleno e integral apoio no então Chefe do Poder Executivo, o Coronel Walter Peracchi Barcellos, e na Egrégia Assembleia Legislativa, que acolheram as proposições do Tribunal e as transformaram em lei” (NEQUETE, 2010, v. I, p. 93 e 95). Em outra entrevista, que integra o projeto Histórias de Vida, há referência ao Código de Organização Judiciária, também elaborado em razão de competência outorgada pela legalidade autoritária: "O COJE de 1966 foi muito bem pensado, bem estudado, principalmente porque aumentou o número de comarcas, Juizados, Varas, etc, que era a nossa grande preocupação" (FÉLIX, 1999. vol. I, p. 180).

16 No mesmo sentido, a referência de Carlos Thompson Flores sobre sua indicação para Ministro do Supremo Tribunal Federal: "Ruy Cirne Lima, este, inclusive, quem me fez a primeira visita quando de minha indicação pelo Presidente Costa e Silva” (FÉLIX, 1999. v. I, p. 156).
} 
autoritária de natureza constitucional e naturalizaram sua aplicação, a memória institucional que menciona a legalidade autoritária nivela a legitimidade das normas. Curiosamente, essa mesma narrativa institucional aponta que o judiciário era um poder independente durante o regime autoritário: “o poder judiciário no Rio Grande do Sul sempre foi, e continua sendo, um poder independente, um poder autônomo, em que os outros poderes não metem a mão" (FÉLIX, 1999, v. I, p. 86).

Esses elementos que tangenciam a narrativa oficial, criada pela justiça comum para contar como foi sua atuação durante o regime autoritário, indicam que o padrão de narração constrói uma memória obrigada. Mais que isso, uma memória, cujos nexos pouco se relacionam com finalidades democráticas, o que insinua o abuso pelo esquecimento de elementos fundamentais para compreensão da intensidade de comprometimento do poder judiciário tem com um projeto constitucional.

\section{CONSIDERAÇÕES FINAIS}

Toda memória deixa um rastro. Ao mesmo tempo em que sua narrativa sedimenta o elo entre os fatos pinçados para compô-la, a erosão avança sobre o que não foi acolhido. Formam- se arquivos tanto para o que se narra, quanto para o que não é narrado. Assim, ao lado da narrativa oficial sobre a atuação do judiciário durante o regime autoritário, há uma infinidade de fontes capazes de desviar, inverter ou complementar essa memória oficial.

Paralelamente, há uma cumplicidade secreta entre quem faz a narrativa oficial e quem se submete a ela, pois as fontes existem. ${ }^{17}$ Esses sentidos permanecerão inertes se não houver disposição para se buscar a memória, para exercê-la, para se narrar de forma diferente e deslocar a atenção para as migalhas deixadas pela narrativa institucional. Portanto, as características que apontam para abusos da memória, insinuados no seu uso, possibilitam que esses abusos possam ser denunciados por outras narrativas.

\footnotetext{
17 No caso da documentação administrativa do poder judiciário durante o regime autoritário e dos processos desse período, as fontes não estão sistematizadas e, não raro, estão em péssimo estado de conservação, ainda que restauradas. Os mecanismos de busca ainda não incluem essas fontes, de forma que as pesquisas requerem um empenho físico do pesquisador. Com sorte, contará com alguém responsável pelo arquivo que, pelos longos anos dedicados ao trabalho naquele espaço, poderá conduzi-lo pelas caixas e pelos corredores dos maltratados e gigantescos arquivos judiciais. Ainda assim, as fontes existem e é possível acessá-las.
} 
Nesse sentido, a postura que considera o abuso de memória apenas um descuido, um lapso, um ato falho, diante da impossibilidade de se narrar tudo, é, antes, uma forma ardilosa de esquecimento, resultante do desapossamento dos agentes sociais do seu poder de narrarem a si mesmos. Portanto, a denúncia dos abusos também depende da reconquista dos agentes sociais do domínio da sua capacidade de fazer narrativa (RICOEUR, 2007, p. 455).

\section{REFERÊNCIAS BIBLIOGRAFICA}

BALEEIRO, Aliomar. O Supremo Tribunal Federal, esse outro desconhecido. Rio de Janeiro: Forense, 1968.

BENJAMIN, Walter. La dialectica en suspenso: fragmentos sobre la historia. Buenos Aires: ARCIS-LOM, 2002.

BIANCAMANO, Mary da Rocha (coord.). As Sedes do Tribunal. Porto Alegre: Tribunal de Justiça do Rio Grande do Sul, s/d.

CATROGA, Fernando. Memória, história e historiografia. Coimbra: Quarteto, 2001. ELIADE, Mircea. Mito e realidade. São Paulo: Perspectiva, 2006.

O mito do eterno retorno: arquétipos e repetição. Lisboa: 70, 1993.

FÉLIX, Loiva Otero. Tribunal de Justiça do RS: mais de um século de história. Porto Alegre: Tribunal de Justiça do Estado do Rio Grande do Sul; Departamento de Artes Gráficas, 2012.

FÉLIX, Loiva Otero; GRIJÓ, Luiz Alberto (org.). Histórias de Vida, Entrevistas e Depoimentos de Magistrados Gaúchos. Porto Alegre: Tribunal de Justiça do Rio Grande do Sul. Projeto Memória do Judiciário Gaúcho, 1999. vol. I.

GIORGIS, José Carlos Teixeira. Prefácio - Uma visão abrangente da Justiça do Rio Grande do Sul. In: FÉLIX, Loiva Otero. Tribunal de Justiça do RS: mais de um século de história. Porto Alegre: Tribunal de Justiça do Estado do Rio Grande do Sul; Departamento de Artes Gráficas,2012.

GIORGIS, José Carlos Teixeira. Prefácio - Uma visão abrangente da Justiça do Rio Grande do Sul. In: HALBWACHS, Maurice. La mémoire collective. Paris: Albin Michel, 2001.

JUSTIÇA FEDERAL. Memorial da Justiça Federal do Rio Grande do Sul. Núcleo de Documentação e Memória Institucional. Justiça Federal/RS: linha do tempo. Porto Alegre: Justiça Federal do Rio Grande do Sul. Folheto. s/d. 
KRIEGER, João César Leitão. A justiça federal no Rio Grande do Sul. In: NEQUETE, Lenine (org.). O poder judiciário no Rio Grande do Sul. Porto Alegre: Tribunal de Justiça do Estado do Rio Grande do Sul; Departamento de Artes Gráficas, 2010. Tomo II.

LEVI, Primo. Les naufragés et les rescapés. Paris: Gallimard, 1989.

MATE, Reyes. Memórias de Auschwitz: atualidade e política. São Leopoldo: Nova Harmonia, 2005.

NEQUETE, Lenine (org.). O poder judiciário no Rio Grande do Sul. Porto Alegre: Tribunal de Justiça do Estado do Rio Grande do Sul; Departamento de Artes Gráficas, 2010. Tomo I.

O poder judiciário no Rio Grande do Sul. Porto Alegre: Tribunal de Justiça do Estado do Rio Grande do Sul; Departamento de Artes Gráficas, 2012. Tomo II. OST, François. O tempo do direito. Lisboa: Instituto Piaget, 2001.

REIS, José Carlos. Tempo, história e evasão. Campinas: Papirus, 1994.

RICOEUR, Paul. A memória, a história, o esquecimento. Campinas: Unicamp, 2007.

RIO GRANDE DO SUL. Ação Ordinária no 80.047. Juízo de Direito dos Feitos da Fazenda Pública. Comarca de Porto Alegre. Requerido: Estado do Rio Grande do Sul. Juiz Hermann Homem de Carvalho Roenick. Julgado em 30 dez. 1968. FONTE: Arquivo Judicial Centralizado do Rio Grande do Sul.

ROSENFELD, Michel. The identity of constitutional subject: selfhood, citizenship, culture and community. London: Routledge, 2010.

SEHNEM, Donato João; BIANCAMANO, Mary (org.). Cadernos de Memória: Athos Gusmão Carneiro. Porto Alegre: Tribunal de Justiça do Estado do Rio Grande do Sul, Departamento de Artes Gráficas. 2009. v. II.

SEHNEM, Donato João; BIANCAMANO, Mary (org.). Cadernos de Memória: Athos Gusmão Carneiro. Porto Alegre: Tribunal de Justiça do Estado do Rio Grande do Sul, Departamento de Artes Gráficas. 2009. v. II.

SOUZA, Nelson Oscar de. Apresentação. In: FÉLIX, Loiva Otero; GRIJÓ, Luiz Alberto (org.). Histórias de Vida, Entrevistas e Depoimentos de Magistrados Gaúchos. Porto Alegre: Tribunal de Justiça do Rio Grande do Sul. Projeto Memória do Judiciário Gaúcho, 1999. vol. I. SUPREMO TRIBUNAL FEDERAL. Solenidade de posse dos ministros José Néri da Silveira, na Presidência, e Aldir Guimarães Passarinho, na Vice-Presidência do Supremo Tribunal Federal. Saudação do senhor Ministro Sydney Sanches. Sessão de 14 de março de 1989. Brasília: Imprensa Nacional, 1989.

TODOROV, Tzvetan. Los abusos de la memoria. Barcelona: Paidós, 2000.

TRIBUNAL DE JUSTIÇA DO RIO GRANDE DO SUL. Memorial do Judiciário do Rio Grande do Sul. Cadernos de Pesquisa: história administrativa das comarcas. Porto Alegre: Tribunal de Justiça do Estado do Rio Grande do Sul, 2003. v. I. 
. Memorial do Judiciário do Rio Grande do Sul. História do Poder Judiciário do Rio Grande do Sul. Porto Alegre: Tribunal de Justiça do Rio Grande do Sul, 2014.

. Memorial do Judiciário. Porto Alegre: Tribunal de Justiça do Rio Grande do Sul. Folheto de divulgação. s/d. 